\title{
Up-scaling aerosol functionalization. Photo-oxychlorination using vacuum ultraviolet radiation (VUV)
}

\author{
José Salas Vicente, ${ }^{\text {a,c }}$ Juan López Gejo, ${ }^{\text {,dd }}$ Sonja Rothenbacher, \\ Sumalekshmy Sarojiniamma, ${ }^{\text {a,e }}$ Eliso Gogritchiani, ${ }^{\text {a,f }}$ Michael Wörner, ${ }^{\text {a,g }}$ \\ Esther Oliveros, ${ }^{\text {a,h }}$ and André M. Braun ${ }^{\text {a* }}$ \\ ${ }^{a}$ Lehrstuhl für Umweltmesstechnik, Engler-Bunte-Institut, Universität Karlsruhe, \\ 76128 Karlsruhe, Germany \\ ${ }^{b}$ Bereich Gas-Partikel-Systeme, Institut für Mechanische Verfahrenstechnik und Mechanik, \\ Karlsruhe Institut für Technologie (KIT), 76128 Karlsruhe, Germany \\ ${ }^{c}$ Present address: UV-Consulting Peschl España S.L., 46980 Paterna (Valencia), Spain \\ ${ }^{d}$ Present address: Departamento de Química Orgánica I, Universidad Complutense \\ de Madrid, 28040 Madrid, Spain \\ ${ }^{e}$ Present address: School of Chemistry and Biochemistry, Georgia Institute of Technology, \\ Atlanta, GA 30332, USA \\ ${ }^{f}$ Present address: Reuter Chemische Apparatebau KG, 79108 Freiburg, Germany \\ ${ }^{g}$ Present address: Institut für Bio- und Lebensmitteltechnik, Bereich IV: \\ Molekulare Aufarbeitung von Bioprodukten, Karlsruhe Institut für Technologie (KIT), \\ 76128 Karlsruhe, Germany \\ ${ }^{h}$ Present address: Laboratoire des IMRCP, UMR CNRS 5623, Université Paul Sabatier \\ (Toulouse III), 31062 Toulouse Cédex 9, France \\ E-mail: Andre.Braun@,ciw.uni-karlsruhe.de
}

\section{Dedicated to Prof. Heinz Heimgartner, University of Zürich, Switzerland, at the occasion of his $70^{\text {th }}$ birthday}

\begin{abstract}
The up-scaling of an earlier described VUV-photochemical oxidative functionalization of polystyrene aerosols depends primarily on the possibility to increase substantially the particle concentration in the gas phase, the aerosol flux and the rate of oxidation. The VUV-photolysis of tetrachloro-methane $\left(\mathrm{CCl}_{4}\right)$ in the presence of air was chosen for the initiation of the oxidation of the polystyrene surface (photo-oxychlorination) taking advantage of the excellent solvent characteristics and the high absorption cross section. FTIR spectroscopic analyses confirm the high efficiency of the process, and chlorination, crosslinking and oxidative particle fragmentation remained at low yields. Secondary products of the VUV-photolysis of $\mathrm{CCl}_{4} \mathrm{were}$ trapped and did not interact with the functionalized particles.
\end{abstract}


Keywords: Polystyrene, particulate aerosol, VUV-photolysis, VUV-photo-oxychlorination, oxidative functionalization

\section{Introduction}

The preparation and functionalization of nanoparticles is one of the top priorities in materials research and development. In addition to the important classical industrial applications (e.g. catalysts, pigments...), new products with exceptional properties are emerging ${ }^{1-3}$. Organic (polymers) and hybrid (e.g. coated inorganic materials) nanoparticles are of primary interest, and corresponding development work already led to a number of applications, e.g. in the biochemical and medical domain (drug and enzyme carriers, ${ }^{4}$ adsorbents, ${ }^{5}$ affinity bioseparators ${ }^{6}$ ) as well as in the optical and optoelectrical domains. ${ }^{7}$

(Photo) chemical processes implying aerosols represent a technical challenge. Several reactors operating in a continuous regime may be lined up to perform a series of subsequent chemical reactions at the particle surface. The overall process may therefore be carried out without separation and purification of the intermediate products and is in line with the aim to develop means of "chemical engineering beyond unit operations". ${ }^{8}$ With respect to the present work and as shown in Figure 1, a monomer may be dispersed into the gas phase as droplet aerosol that is subsequently photochemically polymerized. Passing into a next reactor, the solid aerosol particles may be functionalized by photooxidation. Depending on the project to be accomplished, the nanoparticles may be dispersed into water after this first functionalization, or may be guided into other reactors for a second or even third functionalization. The VUVphotochemical oxidation of polystyrene nanoparticles of defined diameter, the characterization of the oxidized particles and examples of a secondary functionalization have already been reported, ${ }^{9-12}$ and the present work focalizes on the up-scaling of the first functionalization.

For a large-scale production of functionalized particles, higher aerosol concentrations are required. If polymers are to be used as substrate, solutions of these polymers of rather high concentrations are necessary. Such solutions might be prepared by dissolving the polymer in supercritical $\mathrm{CO}_{2}$ to be subsequently expanded into an $\mathrm{O}_{2}$ containing gas phase at ambient pressure (Rapid Expansion of Supercritical Solutions (RESS) ${ }^{13}$ ). This method of aerosol generation might however show the disadvantage to leave an insufficient $\mathrm{O}_{2}$ concentration for the subsequent photochemical oxidation of the particle surfaces. Alternatively, suitable solvents might be used to prepare polymer solutions to be sprayed into heated gas streams. As the solvent evaporates, polymer aerosol particles of nanoscale dimensions will be generated. However, only solvents that do not interfere with the subsequent photochemical oxidation are really useful. 


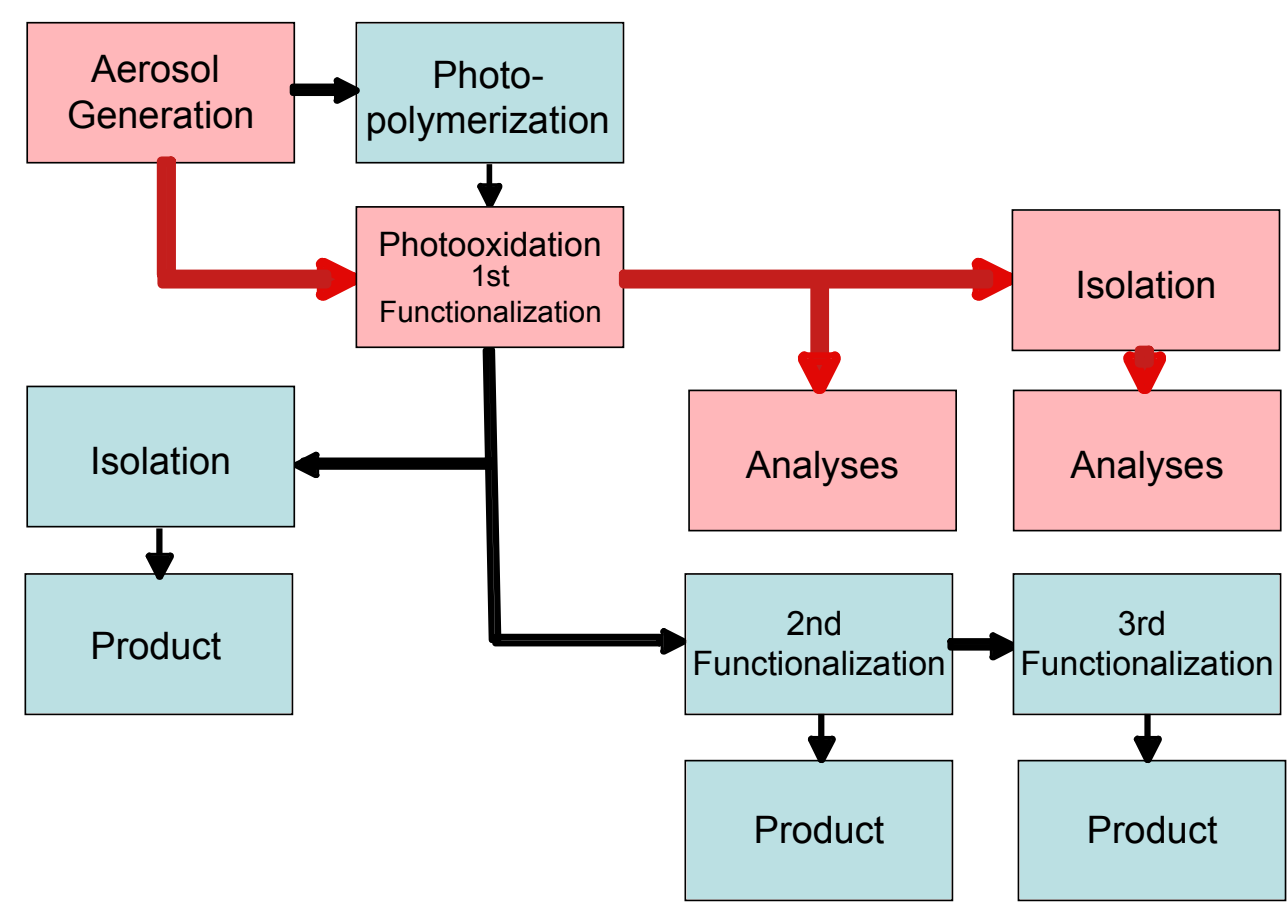

Figure 1. Operational scheme for a sequence of chemical processes using organic aerosol particles. The elements used in this work are shown in red.

Similar problems arise when monomers are used instead. VUV-photochemical polymerization of vinyl monomers in $\mathrm{O}_{2}$-free condensed phase has been reported, ${ }^{14}$ and its rate could be enhanced with the use of initiators dissolved in the liquid monomer or co-dissolved in $\mathrm{CO}_{2} . \mathrm{O}_{2}$ would have to be added to the aerosol stream at sufficiently high concentration in order to perform a subsequent photochemical oxidation with high efficiency. De-oxygenated monomer solutions might be sprayed into $\mathrm{O}_{2}$-free gas streams provided that the solvent would not interfere with the initiated radical polymerization.

VUV-radiation in the presence of $\mathrm{O}_{2}$ was found to oxidize polystyrene surfaces with high efficiency. ${ }^{11,12,14 \mathrm{~d}-16}$ VUV-radiation $(172 \mathrm{~nm})$ is absorbed by almost all constituents of the reaction system generating a number of highly reactive intermediates. The most important primary reaction of the VUV-photochemical oxidation of polymers in the gas phase was found to proceed by the homolysis of $\mathrm{C}$-C-bonds of the polymer substrate. In the case of polystyrene, backbone fragmentation led to secondary and tertiary $\mathrm{C}$-centered radicals (reaction (1)). Gaseous components of the reaction systems absorbing VUV-radiation were $\mathrm{O}_{2}$ and $\mathrm{H}_{2} \mathrm{O}$. VUVphotolysis of $\mathrm{O}_{2}$ generates atomic oxygen $(\mathrm{O})$ (reaction (2)) ${ }^{17}$ that is known to react from both triplet and singlet states with organic substrates by hydrogen abstraction (reaction (3)); the latter may also react by insertion into a C-H-bond (reaction (4)). ${ }^{18,19}$ However, O predominantly adds to $\mathrm{O}_{2}$ yielding ozone $\left(\mathrm{O}_{3}\right)$ (reaction $\left.(5)\right) .^{17}$ 


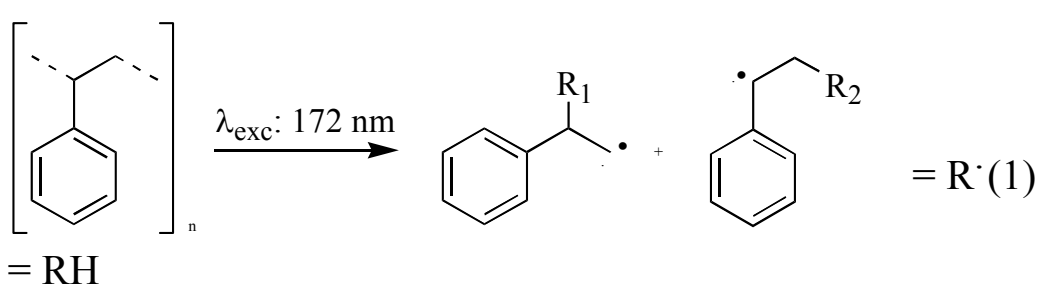

$$
\begin{aligned}
& \mathrm{O}_{2}+\mathrm{hv}(\mathrm{VUV}) \longrightarrow 2 \mathrm{O} \\
& \mathrm{O}+\mathrm{RH} \longrightarrow \mathrm{R}^{\cdot}+\mathrm{HO}^{\bullet}(3) \\
& \mathrm{O}+\mathrm{RH} \longrightarrow \mathrm{ROH}^{(4)} \\
& \mathrm{O}+\mathrm{O}_{2} \longrightarrow \mathrm{O}_{3}
\end{aligned}
$$

The VUV-photolysis of $\mathrm{H}_{2} \mathrm{O}$ was described in detail ${ }^{20}$ and may be used to initiate the oxidation of organic compounds by intermediate hydroxyl (HO') radicals (reaction (6)) via hydrogen abstraction (reaction (7)) and addition to $\pi$-systems (reaction (8)) generating Ccentered radicals.

$$
\begin{aligned}
& \mathrm{H}_{2} \mathrm{O}+\mathrm{h} v(\mathrm{VUV}) \longrightarrow \mathrm{H}^{\bullet}+\mathrm{HO}^{\bullet} \\
& \mathrm{HO}^{\bullet}+\mathrm{RH} \longrightarrow \mathrm{R}^{\bullet}+\mathrm{H}_{2} \mathrm{O} \quad(7) \\
& \mathrm{HO}^{\circ}+\mathrm{RR}^{\prime} \mathrm{C}=\mathrm{CR}^{\prime}{ }^{\prime} \mathrm{R}^{\prime},{ }^{\prime} \longrightarrow \mathrm{RR}^{\prime} \mathrm{C}^{\bullet}-\mathrm{C}(\mathrm{OH}) \mathrm{R}^{\prime}{ }^{\prime} \mathrm{R}^{\prime},
\end{aligned}
$$

C-Centered radicals are trapped by $\mathrm{O}_{2}$ (reaction (9)) generating peroxyl radicals $\left(\mathrm{RO}_{2}{ }^{\circ}\right)$ that, depending on their structure and on the reaction conditions, produce, in a manifold of thermal reactions, hydroxyl, carbonyl or carboxyl functions (reactions (10) and (11)). Carboxyl functions are known to react with $\mathrm{HO}^{\bullet}$ by electron transfer and subsequent decarboxylation (reactions (12) and (13), respectively). ${ }^{21}$

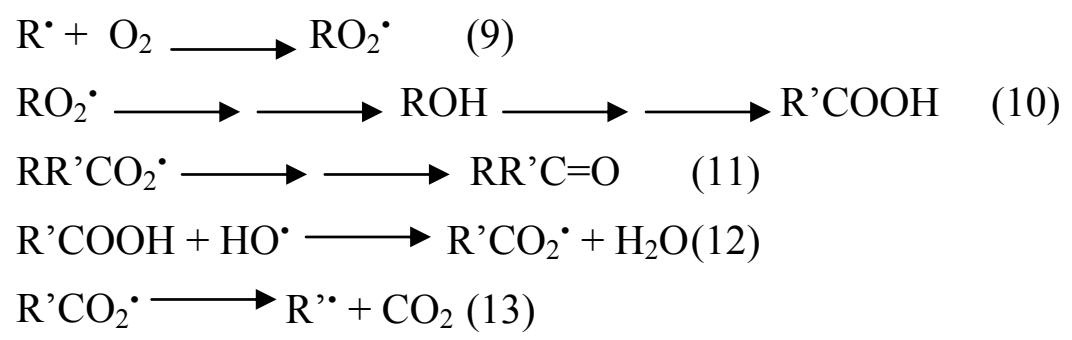

Although, $\mathrm{O}_{3}$ is not photolyzed under the experimental conditions applied, it was found to oxidize polystyrene surfaces. ${ }^{14 \mathrm{~d}, 16}$ The oxidation, mechanistically not elucidated so far, proceeded at a slower rate than the combination of reactions (1), (9), (10) and (11). The evolution of the hydroxyl and carbonyl functions was found to be linear with reaction time, recommending ozonolysis of polymer aerosol particles for a controlled oxidative 
functionalization. Nevertheless, expecting that at higher particle concentrations a larger concentration of $\mathrm{O}_{3}$ would be needed to maintain the rate of oxidation, it might be difficult to eliminate the excess, before the reaction system would enter a next reactor (secondary functionalization).

Reactions (1), (9) and (10) demonstrate that the VUV-photochemical oxidation of polystyrene surfaces involves several parallel and subsequent processes that lead in a first step via fragmentation of the backbone of the polymer or via hydrogen abstraction to the production of hydroxyl and carbonyl functions (oxidative functionalization). In subsequent steps, these intermediate products are further oxidized and eventually yield carboxylic acids of low molecular weight and $\mathrm{CO}_{2}$ (mineralization). In a technical development of the functionalization process, conditions must be found that enhance oxidative functionalization and shorten the time of irradiation (residence time) in order to stop further oxidative degradation at an early state. In fact, diminution of particle diameter and concentration got faster as the residence time was increased. Expectedly, the same result was found with an increasing incident photon flux ${ }^{9,11,12}$. The solution might be found with the use of a photoinitiator that a priori would not react via backbone fragmentation. Hydrogen abstraction might however be strongly enhanced with the use of a suitable initiator whose concentration could be adapted to the mass of substrate to be oxidized within a restricted time of irradiation (residence time).

Photo-oxychlorination $^{22}$ has, so far, rarely been used as a means of preparative photochemistry. The corresponding sequence of reactions (14), (15), (9), (10) and/or (11) is mostly known as a secondary reaction manifold during photochlorination of not properly de-oxygenated reaction systems.

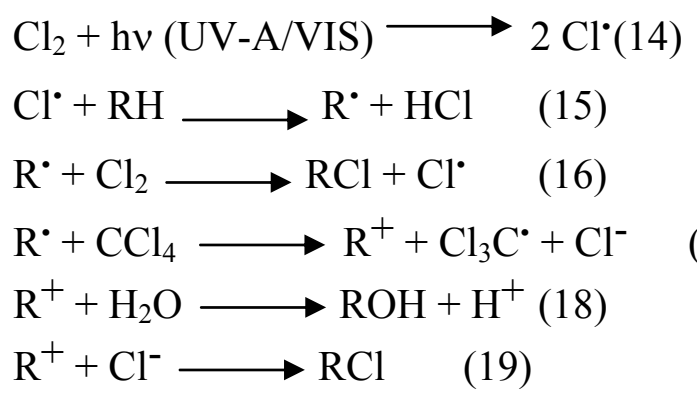

Chlorine atoms $\left(\mathrm{Cl}^{\circ}\right)$ are generated photochemically as initiators (reaction (14)) and react by hydrogen abstraction with the substrate (reaction (15)). In an $\mathrm{O}_{2}$-free reaction system, monochlorination is completed by reaction (16), whereas in the presence of $\mathrm{O}_{2}$, the intermediate $\mathrm{C}$ centered radical is primarily trapped producing the corresponding peroxyl radical (reaction (9)). The oxidation of the organic substrate is completed as shown with reactions (10) and (11), and the fragmentation processes is delayed to the subsequent oxidation of the produced hydroxyl and carbonyl functions. Earlier investigations in aqueous phase showed that $\mathrm{C}$-centered radicals react with $\mathrm{CCl}_{4}$ yielding the corresponding carbonium ions, trichloro-methyl radicals $\left(\mathrm{Cl}_{3} \mathrm{C}^{*}\right)$ and 
chloride (reaction (17)) ${ }^{23} \cdot \mathrm{R}^{+}$might be solvolyzed to yield the corresponding alcohol (reaction (18)), but the generation of $\mathrm{R}^{+}$might also contribute to the chlorination of the substrate (reaction 19).

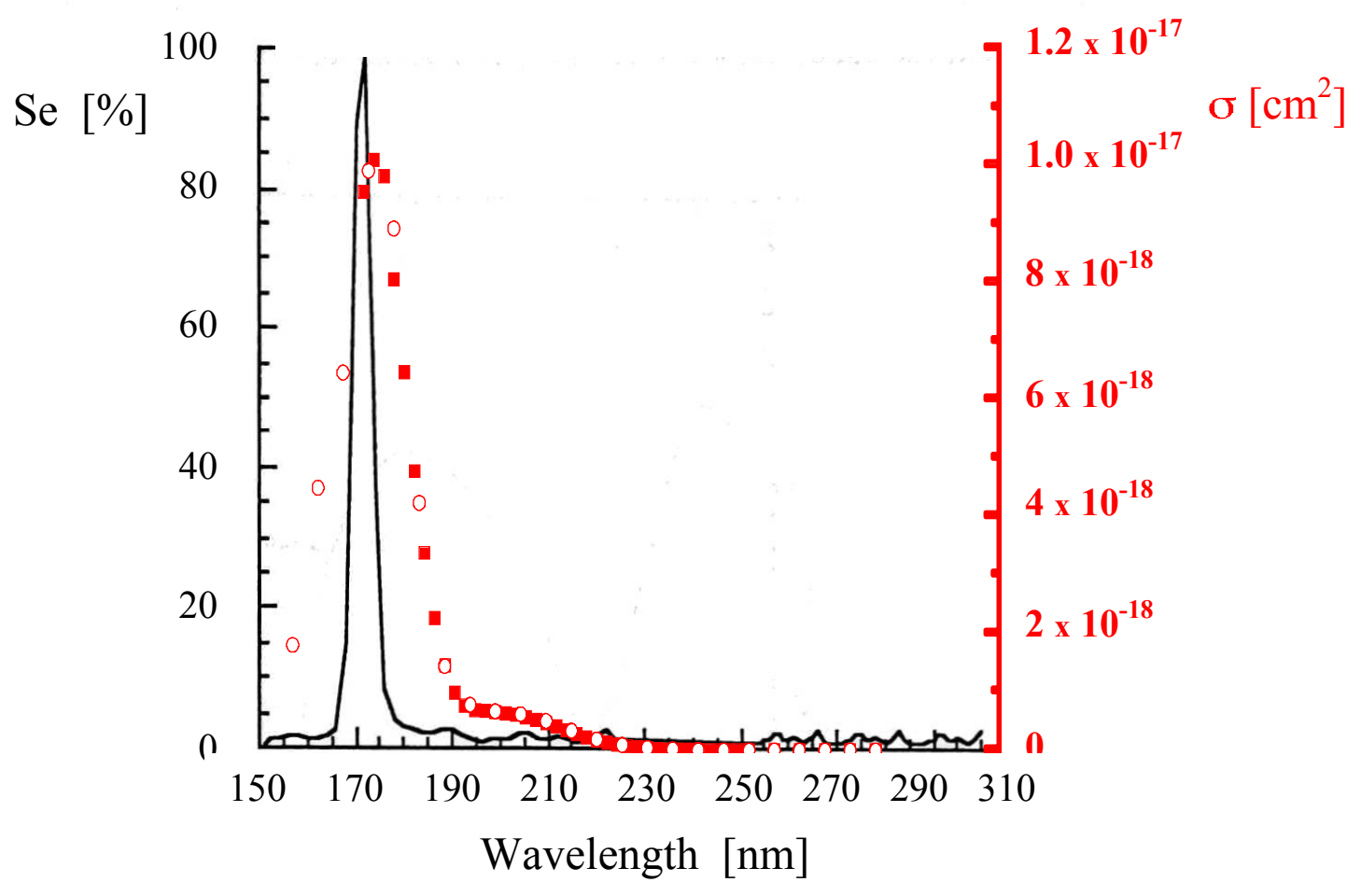

Figure 2. Normalized emission spectrum of the $\mathrm{Xe}_{2}$-excimer radiation source used in this work (black), and absorption cross section $(\sigma)$ of $\mathrm{CCl}_{4}$ in the VUV-and UVC-spectral regions (red).

Molecular chlorine $\left(\mathrm{Cl}_{2}\right)$ does not absorb in the VUV-spectral domain, but most alkyl chlorides do. Tetrachloro-methane $\left(\mathrm{CCl}_{4}\right)$ is an excellent solvent for polystyrene and exhibits a strong absorption cross section at the wavelength of excitation (172 nm, Figure 2). Electronic excitation leads to the homolysis of the C-Cl-bond (reaction (20)) with a quantum yield of approx. $1^{24}$, hence, efficiently generating $\mathrm{Cl}^{*}$ for the initiation of the oxidative functionalization.

$\mathrm{CCl}_{4}+\mathrm{hv}(\mathrm{VUV}) \longrightarrow \mathrm{Cl}^{\bullet}+\mathrm{Cl}_{3} \mathrm{C}^{\bullet}(20)$ 


\section{Results and Discussion}

\section{Particle concentration and diameter}

Concentration and size of polystyrene aerosol particles generated by spraying a $\mathrm{CCl}_{4}$-solution into a hot gas stream are expected to depend primarily on equipment settings and gas flow and temperature. However, the data shown in Figure 3 demonstrate that particle concentration $\left(c_{\text {part }}\right)$ and diameter $(2 r)$ vary as a function of the polystyrene concentration in $\mathrm{CCl}_{4}\left(c_{\mathrm{PS}}\right)$. For $c_{\mathrm{PS}}<1,5$ $\mathrm{g} \mathrm{L}^{-1}, c_{\text {part }}$ increased rapidly with $c_{\mathrm{PS}}$, but reached a maximum at $c_{\mathrm{PS}}=4 \mathrm{~g} \mathrm{~L}^{-1}$. Assuming that under the invariant experimental conditions, the number of aerosol droplets would not change by varying $c_{\mathrm{PS}}$, droplets might split into a large number of solvated particles, as $\mathrm{CCl}_{4}$ evaporates. At $c_{\mathrm{PS}}>4 \mathrm{~g} \mathrm{~L}^{-1}$, the $c_{\text {part }}$ decreased, and it might be expected that, in this domain of $c_{\mathrm{PS}}$, particles would aggregate. In fact, the particle size (diameter) turned after a rapid increase $\left(c_{\mathrm{PS}}<1.5 \mathrm{~g} \mathrm{~L}^{-1}\right)$ into a linear dependence on $c_{\mathrm{PS}}, 2 r$ increasing with approximately $7 \mathrm{~nm} \mathrm{~L} \mathrm{~g}^{-1}$. The two functions deviate from the initial step slope at the same $c_{\mathrm{PS}}\left(1.5 \mathrm{~g} \mathrm{~L}^{-1}\right)$, and particle aggregation is observed at $c_{\text {part }}>5 \times 10^{6}$ part $\mathrm{cm}^{-3}$. A working $\mathrm{c}_{\mathrm{PS}}$ of $8 \mathrm{~g} \mathrm{~L}^{-1}$ was chosen arbitrarily.

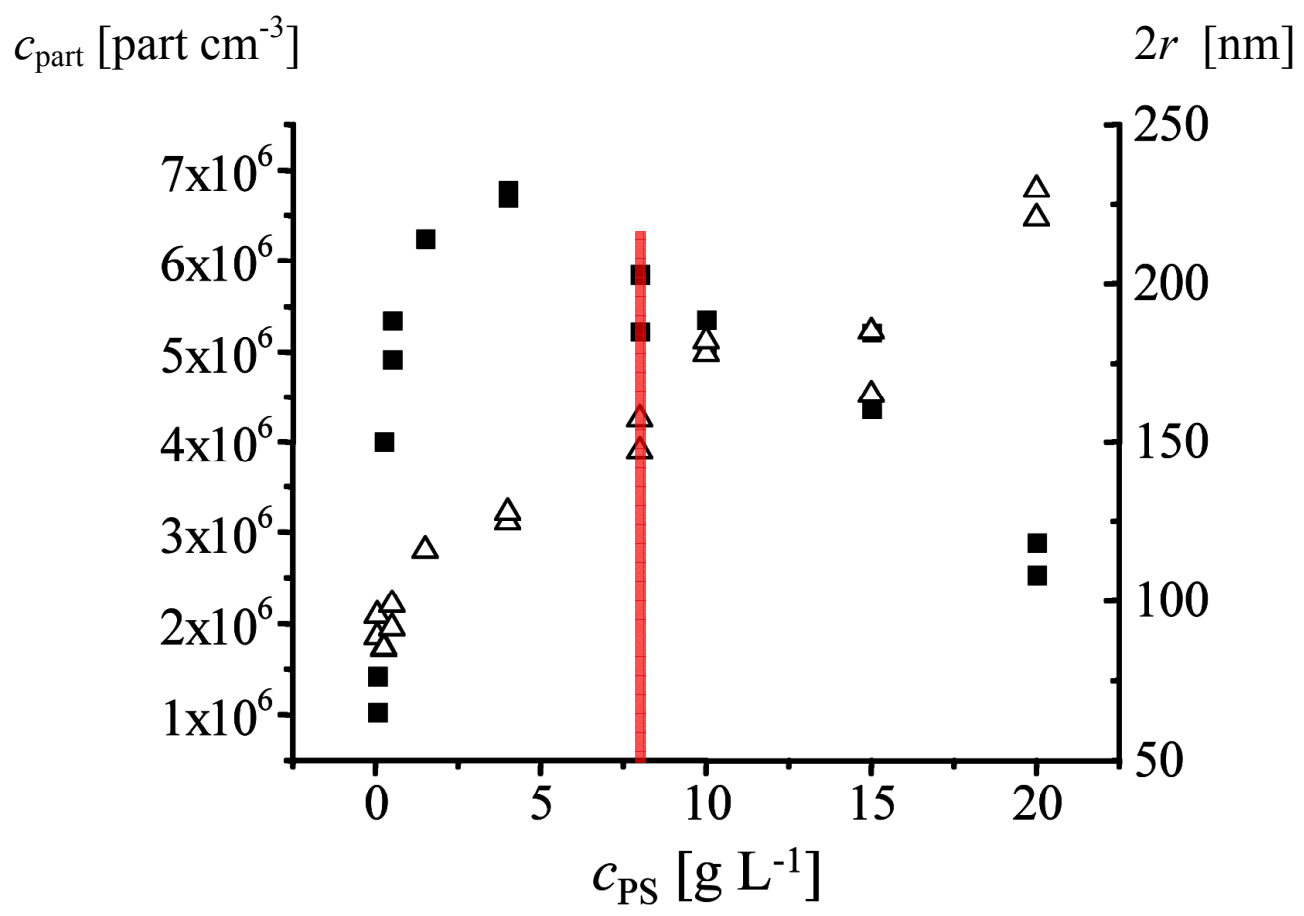

Figure 3. Aerosol generation. Particle concentration $\left(c_{\text {part }}, \mathbf{\square}\right)$ and particle diameter $(2 r, \triangle)$ as a function of the polystyrene concentration $\left(c_{\mathrm{PS}}\right)$ in $\mathrm{CCl}_{4}$. Red line: working $c_{\mathrm{PS}}$. 


\section{Efficiency of photo-oxychlorination}

The oxidation index $I_{\mathrm{ox}(\mathrm{C}=\mathrm{O})}$ calculated from the IR absorption of the produced carbonyl functions is taken as a means to estimate the progress of the oxidative functionalization of the polystyrene particles ${ }^{14 \mathrm{~d}, 12,15}$. Depending primarily on the electrical power of the radiation source $\left(P_{\mathrm{e}}\right)$, the time of irradiation (residence time $(\tau)$ ), the concentrations of oxygen $\left(\left[\mathrm{O}_{2}\right]\right)$ and/or $\mathrm{CCl}_{4}\left(\left[\mathrm{CCl}_{4}\right]\right)$ in the gas phase, the concentration of polystyrene $\left(c_{\mathrm{PS}}\right), I_{\mathrm{ox}(\mathrm{C}=0)}$ evolves toward a limiting value with increasing incident radiant energy $\left(Q_{\mathrm{e}}\right)^{12}$. For a given flux of the aerosol $(F)$, e.g. $7 \mathrm{~L} \mathrm{~min}^{-1}$, maximum values of $I_{\mathrm{ox}(\mathrm{C}=\mathrm{O})}$ may therefore be determined for a predefined electrical power (e.g. $\left.P_{\mathrm{e}}=150 \mathrm{~W}\right)$. Comparing the maximum values of $I_{\mathrm{ox}(\mathrm{C}=\mathrm{O})}$ resulting from the photooxychlorination with those found when polystyrene particles of defined diameter were sprayed into the gas phase and oxidized by VUV-photolysis (Figure 4), the latter process seems more efficient by a factor of 2 .

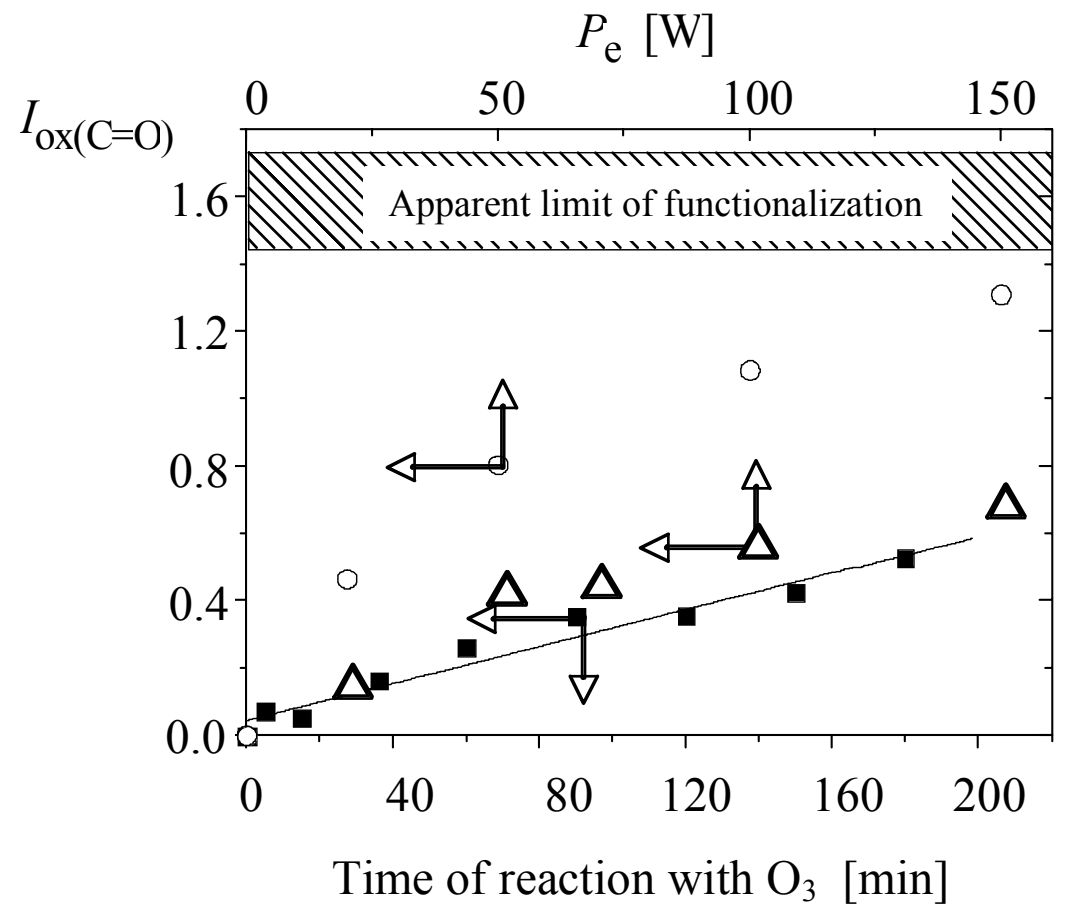

Figure 4. Oxidative functionalization of polystyrene aerosol particles by VUV-photolysis, photo-oxychlorination and ozonization. Maximum oxidation indices $I_{\mathrm{ox}(\mathrm{C}=\mathrm{O})}$ depending on the electrical power of the $\mathrm{Xe}_{2}$-excimer radiation source $\left(P_{\mathrm{e}}\right) . F: 7 \mathrm{~L} \mathrm{~min}^{-1} ; T$ : approx. $60{ }^{\circ} \mathrm{C}$. VUVphotolysis (O): $c_{P S}$ (suspended in $\mathrm{H}_{2} \mathrm{O}$ ): $3.84 \times 10^{-4} \mathrm{~g} \mathrm{~L}^{-1} ; 2 r$ : approx. $500 \mathrm{~nm}$; pressure at the atomizer: 3 bar; composition of gaseous bulk phase (in $\mathrm{N}_{2}$ ): $\left[\mathrm{O}_{2}\right]: 7.5( \pm 0.4) \times 10^{-3}$ M. Photooxychlorination $(\triangle)$ : $\mathrm{c}_{\mathrm{PS}}$ (dissolved in $\left.\mathrm{CCl}_{4}\right): 8 \mathrm{~g} \mathrm{~L}^{-1} ; 2 r$ : approx. $150 \mathrm{~nm}$; pressure at the atomizer: 1 bar; composition of gaseous bulk phase (in $\mathrm{N}_{2}$ ): $\left[\mathrm{CCl}_{4}\right]: 1.5( \pm 0.2) \times 10^{-3} \mathrm{M},\left[\mathrm{O}_{2}\right]$ : 7.5( \pm 0.4$) \times 10^{-3}$ M. Ozonolysis ( $\square$ ): $\mathrm{c}_{\mathrm{PS}}$ (suspended in $\mathrm{H}_{2} \mathrm{O}$ ): $3.84 \times 10^{-4} \mathrm{~g} \mathrm{~L}^{-1} ; 2 r$ : approx. $500 \mathrm{~nm}$; pressure at the atomizer: 3 bar; composition of gaseous bulk phase (in synthetic air): $\left[\mathrm{O}_{3}\right]$ : $3.7( \pm 0.4) \times 10^{5} \mathrm{M}^{12}$. 
However, in photo-oxychlorination experiments, the mass of substrate sprayed into the gas phase was at any time larger by a factor of approx. $10^{4}$. A more precise evaluation of the efficiency of the photo-oxychlorination, with respect to that of the VUV-photolysis taken as a standard, would have to imply the organic surfaces involved that pass through the irradiated

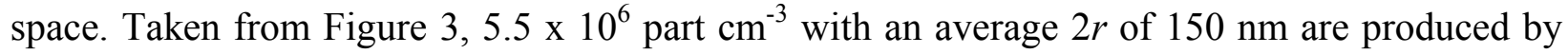
spraying a solution of $8 \mathrm{~g} \mathrm{~L}^{-1}$ of polystyrene in $\mathrm{CCl}_{4}$ into the gas phase. In contrast, only $3.84 \mathrm{x}$ $10^{-4} \mathrm{~g} \mathrm{~L}^{-1}$ of polystyrene particles $(2 r=500 \mathrm{~nm})$ could be maintained in aqueous suspension, and, assuming that the aerosol generation would not alter the size of the particles, $\mathrm{c}_{\text {part }}$ could be

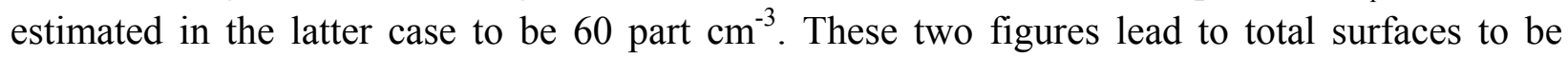
functionalized of $3.9 \times 10^{-7}$ (photo-oxychlorination) and $4.7 \times 10^{-11} \mathrm{~m}^{2}$ (VUV-photolysis), respectively. The resulting factor of $8 \times 10^{3}$ has to be corrected for the different times of residence $\tau$. In fact, due to a large excess of the rate of incident photons $\left(P_{0}, 172 \mathrm{~nm}\right)$ with respect to $c_{\text {part }}$, the length of the irradiated space $d$ (and consequently residence time $\tau^{12}$ ) had to be reduced in the case of the VUV-photolysis to $15 \%$ of the maximum values. Between the two techniques of oxidative functionalization remains therefore a ratio of efficiencies of approx. $10^{3}$.

\section{Photo-oxychlorination vs. photochlorination}

In the reaction manifold of the photochlorination, the $\mathrm{C}$-centered radicals $\left(\mathrm{R}^{\circ}\right)$ at the polystyrene surface react with $\mathrm{Cl}_{2}$ to yield a chlorinated substrate $(\mathrm{RCl}$, reaction (16)). During photooxychlorination, reaction (16) competes against reaction (9), the latter being favoured by a higher rate constant and, in the present case, by a higher $\left[\mathrm{O}_{2}\right]$. Using $\mathrm{CCl}_{4}$ as a precursor of the initiator $\mathrm{Cl}^{\bullet}, \mathrm{R}^{\bullet}$ might combine with $\mathrm{Cl}_{3} \mathrm{C}^{\bullet}$ (reaction (21)) but also with $\mathrm{Cl}_{2}$, produced by the fast recombination of two $\mathrm{Cl}^{\bullet}$ (reaction (22)). The rates of the reactions (9), (17), (21), (22) and (16), subsequent to hydrogen abstraction (reaction (15)), could be affected by varying $\left[\mathrm{O}_{2}\right]$. However, an increase of $\left[\mathrm{O}_{2}\right]$ would diminish the rate of the VUV-photochemical homolysis of $\mathrm{CCl}_{4}$ and favour the production of $\mathrm{O}_{3}$, known to be a less efficient oxidant. It was therefore decided to stay with the use of synthetic air as the most economic reagent for this kind of technical development.

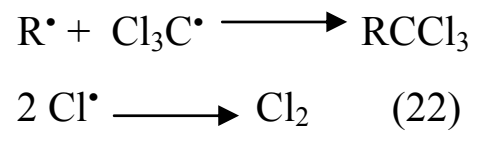

Reactions (16), (19) and (21) produce chlorinated polymer products that in principle could be analyzed by NMR spectroscopy or by a combination of LC/MS. However, the masses of particles produced and isolated were too small, and it was decided to evaluate the extent of the chlorinated products in the final mixture of particles by X-Ray Photoelectron Spectroscopy (XPS). Figure 5 shows the spectra of native and photo-oxychlorinated polystyrene. The two photo-oxychlorinated samples differ by $P_{\mathrm{e}}$ and $\tau$ applied, and the increase of the measured signals $\left(I_{\mathrm{app}}\right)$ of the chlorine peak reflects the higher concentration of chlorinated products as the 
two parameters are increased. It might be expected that a simultaneous increase of $P_{\mathrm{e}}$ and $\tau$ produces higher steady state concentrations of $\mathrm{Cl}^{\circ}$ and $\mathrm{Cl}_{3} \mathrm{C}^{\cdot}$ as well as $\mathrm{R}^{*}$. An enhanced oxidation of $\mathrm{R}^{\cdot}$ (reaction (9)) would provoke a diminution of $\left[\mathrm{O}_{2}\right]$ in the irradiated space along the flux of the aerosol and consequently favor the production of chlorinated compounds.

Subtraction of the respective background signals from of the different signals $I_{\text {app,i }}$ and normalization of the corrected $I_{\text {app,i }}^{\prime}$ for the respective absorption cross sections of photoionization $\sigma_{i}$ yield $I_{\text {corr,i }}$ (equation (23)) from which the content of the species to be analyzed $\left(x_{\mathrm{i}}\right)$ is calculated by using equation (24). Table 1 shows the values of $\sigma_{\mathrm{i}}$ used and the contents of $(i=\mathrm{Cl})$ for the two different radiant energies $\left(Q_{\mathrm{e}}\right)$ chosen. Indeed, reaction (9) is getting less competitive as $Q_{\mathrm{e}}$ is increased, and further development efforts would require the optimization of the primary reaction parameters $\mathrm{P}_{\mathrm{e}}, \mathrm{c}_{\mathrm{PS}}$ and $\tau$ in order to minimize the chlorinated products for a maximum of functionalized particles.

$$
\begin{gathered}
I_{c o r r, i}=\frac{I_{a p p, i}^{\prime}}{\sigma_{i}} \\
x_{i}=\frac{I_{c o r r, i}}{\sum_{i}^{n} I_{c o r r, i}}
\end{gathered}
$$

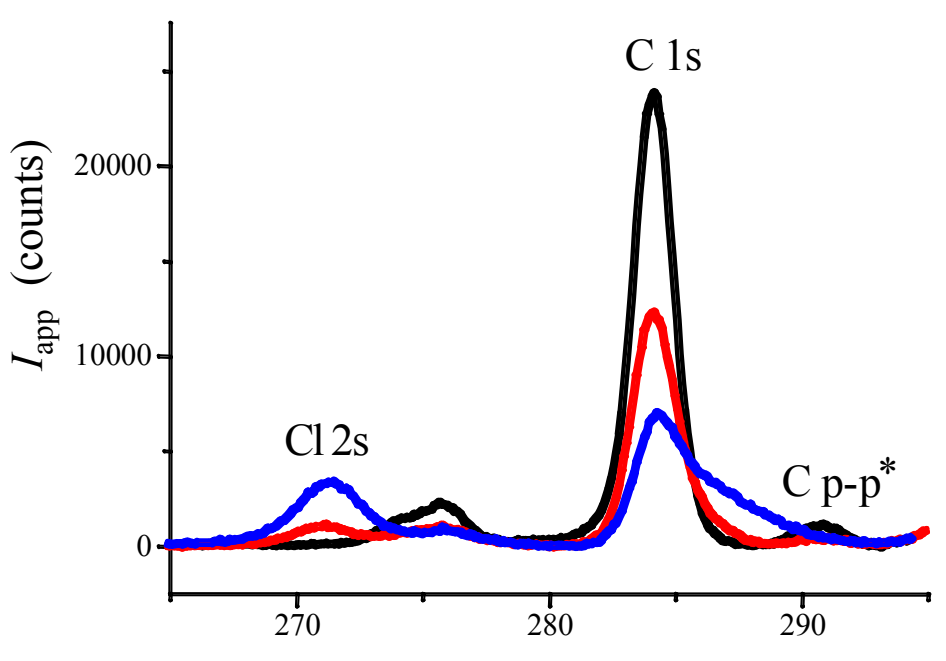

Binding Energy [eV]

Figure 5. X-Ray photoelectron spectra (XPS) of photo-oxychlorinated polystyrene particles. Photoelectron energy: $(1253.6 \mathrm{eV}) .(\longrightarrow): P_{\mathrm{e}}=0 \mathrm{~W}$ (native polystyrene); $\left(\longrightarrow P_{\mathrm{e}}=100 \mathrm{~W}, d: 4\right.$ $\mathrm{mm} ;(\longrightarrow): P_{\mathrm{e}}=150 \mathrm{~W}, d: 4 \mathrm{~mm} . F: 7 \mathrm{~L} \mathrm{~min}^{-1} ; T$ : approx. $60^{\circ} \mathrm{C}, c_{\mathrm{PS}}$ (dissolved in $\left.\mathrm{CCl}_{4}\right): 8 \mathrm{~g} \mathrm{~L}^{-1}$; $2 r$ : approx. $150 \mathrm{~nm}$; pressure at the atomizer: 1 bar; composition of gaseous bulk phase (in $\mathrm{N}_{2}$ ): $\left[\mathrm{CCl}_{4}\right]: 1.5( \pm 0.2) \times 10^{-3} \mathrm{M},\left[\mathrm{O}_{2}\right]: 7.5( \pm 0.4) \times 10^{-3} \mathrm{M}$. 
Table 1. Absorption cross sections of photoionization $\sigma_{\mathrm{i}}$ and contents of $\mathrm{Cl}\left(x_{\mathrm{Cl}}\right)$ calculated from the X-Ray photoelectron spectra of photo-oxychlorinated polystyrene particles. Photoelectron energy $\left(\mathrm{E}_{\mathrm{h} v}\right): 1253.6 \mathrm{eV}$

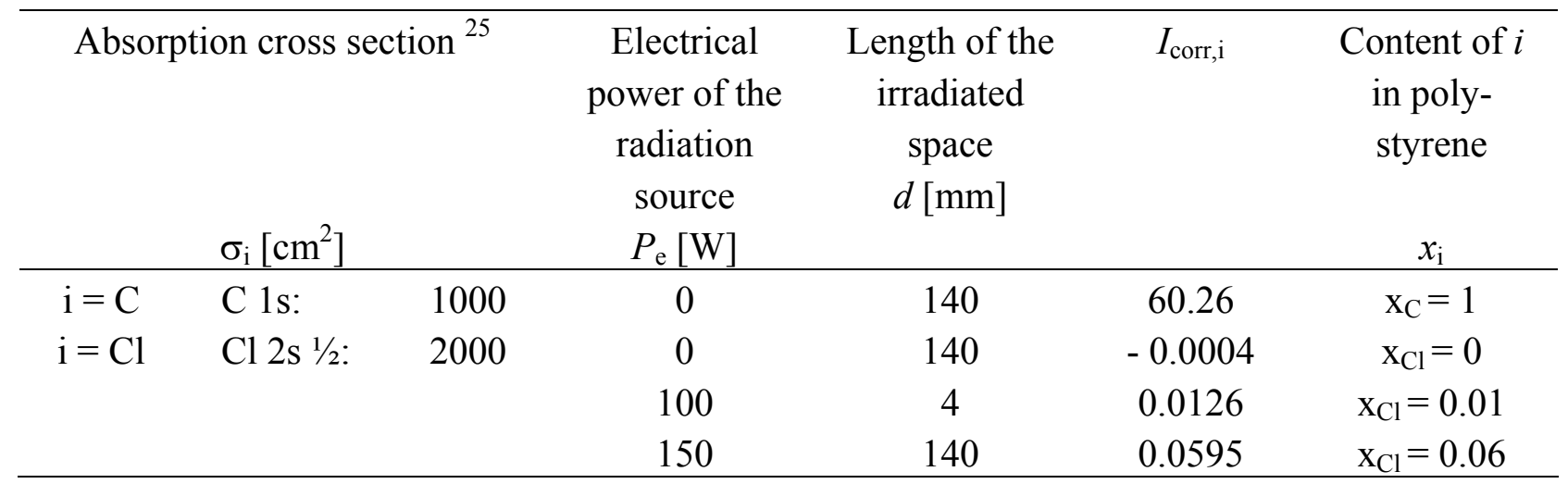

\section{Change of particle characteristics during photo-oxychlorination}

Earlier work on polystyrene films and particles confirmed that the VUV-photochemical oxidation of polystyrene particles suspended in an $\mathrm{O}_{2}$-containing gas phase will continue after a primary surface functionalization und will finally lead to a complete oxidation (mineralization) of the organic substrate. Under conditions of photo-oxychlorination, the rate of photons absorbed by the polystyrene surfaces is reduced, as part of the incident photon flux $\left(P_{\mathrm{e}}\right)$ being absorbed by $\mathrm{CCl}_{4}$ present in the gas phase. In addition, it cannot be excluded that $\mathrm{CCl}_{4}$ is also adsorbed at the particle surfaces. $\mathrm{CCl}_{4}$ and $\mathrm{O}_{2}$ exhibit absorption cross sections at $172 \mathrm{~nm}$ of $4.3 \times 10^{-18} \mathrm{~cm}^{22}$ and $7.7 \times 10^{-19} \mathrm{~cm}^{22}$, respectively. Consequently, the transmittance of a gas phase containing only $\mathrm{O}_{2}$ is reduced to $20 \%$, when $\mathrm{CCl}_{4}$ is added at equal concentration. It might therefore be expected that the rate of the VUV-photolysis of polystyrene particles would be considerably diminished resulting in a less pronounced homolytic fragmentation of the polymer backbone. However, the results do not confirm this working hypothesis, as $c_{\text {part }}$ diminished under conditions of photo-oxychlorination as well as of VUV-photolysis in the presence of oxygen to $90 \%$ of the initial value $\left(P_{\mathrm{e}}: 150 \mathrm{~W}, F: 7 \mathrm{~L} \mathrm{~min}^{-1}\right)$. The result may be explained by an increased reactivity of higher concentrations of alkyl radicals by dismutation and subsequent oxidation of intermediately produced backbone $\pi$-bonds. Figure 6 shows the gel permeation chromatogram (GPC) of photo-oxychlorinated polystyrene in which particle fragmentation as well as particle cross-linking may be observed with the additional peaks and shoulders of lower and higher molecular weights than that of the main peak.

\section{Secondary reactions of the photo-oxychlorination of polystyrene}

The gas phase of the aerosol transported a series of secondary products to cooling traps installed at the end of the process unit. Product identification by GC/MS-analysis of the condensate was not successful for experiments in the presence of $\mathrm{O}_{2}$. However, the manifold of secondary reactions could be shown in irradiating the polystyrene aerosol particles in $\mathrm{N}_{2}$ to which $\mathrm{CCl}_{4}$ was 
added $\left(\left[\mathrm{CCl}_{4}\right]: 1.5( \pm 0.2) \times 10^{-3} \mathrm{M}\right)$. In the absence of $\mathrm{O}_{2}$, the condensate contained products that originate from aromatic substitution (chloro-styrene) and from addition of $\mathrm{Cl}^{\circ}$ to the styrene $\pi$ bond (1,2-dichloro-ethylbenzene). Under the same conditions, $\mathrm{Cl}_{3} \mathrm{C}^{\cdot}$ recombined to hexachloroethane. $\mathrm{Cl}_{3} \mathrm{C}^{\cdot}$ also seems to react by hydrogen abstraction and loss of further $\mathrm{Cl}^{*}$ because products of its combination with $\mathrm{ClH}_{2} \mathrm{C}^{*}$ and $\mathrm{Cl}_{2} \mathrm{HC}$, yielding tetra- and pentachloro-ethane, respectively, were found. Differently chlorinated acetones as well as phosgene showed that traces of $\mathrm{O}_{2}$ were still present in the gas flow, and it may be assumed that these chlorinated carbonyl compounds would be dominant under oxidative experimental conditions. Their high photochemical and thermal reactivity would however lead to a large manifold of reactions producing a complex mixture of products from which only few could be identified. Phosgene and chloro-acetones are easily hydrolyzed from the off-gas of the production unit.

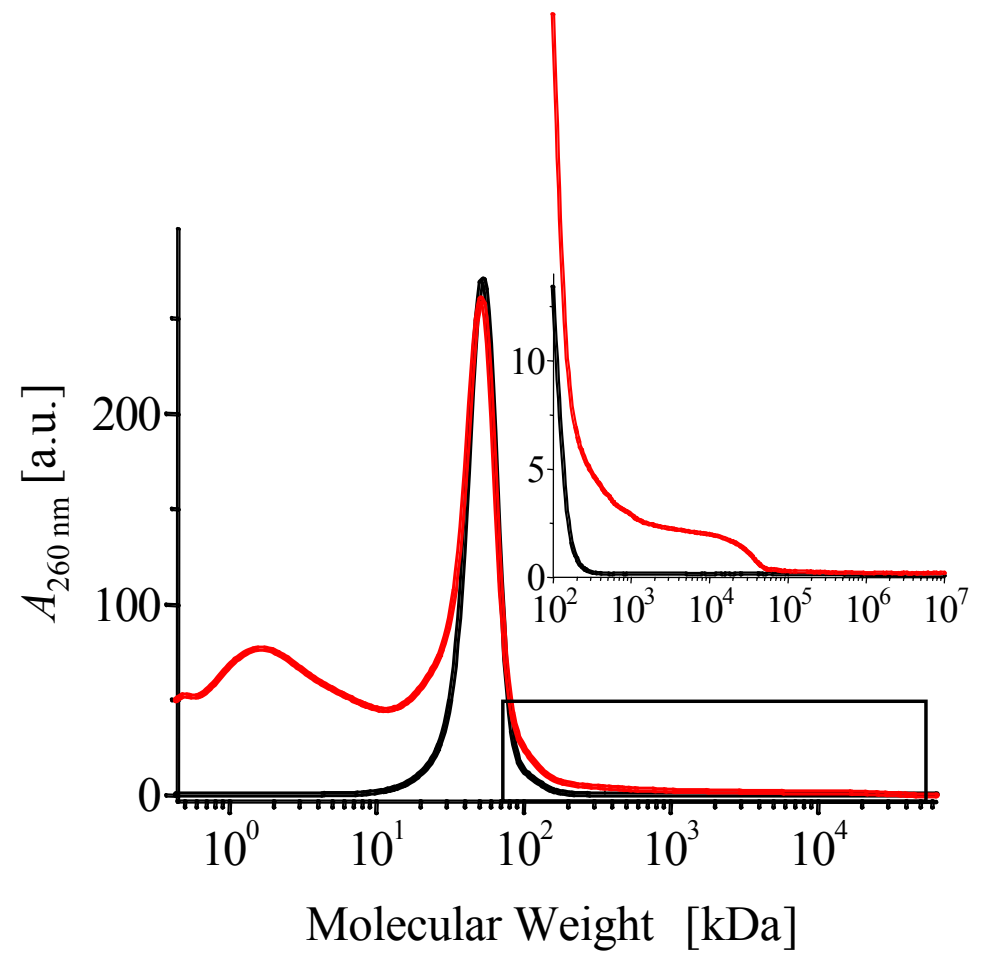

Figure 6. Gel permeation chromatogram (CPG) of photo-oxychlorinated polystyrene particles. $F$ : $7 \mathrm{~L} \mathrm{~min}^{-1} ; T$ : approx. $60^{\circ} \mathrm{C}, c_{\mathrm{PS}}$ (dissolved in $\mathrm{CCl}_{4}$ ): $8 \mathrm{~g} \mathrm{~L}^{-1} ; 2 r$ : approx. $150 \mathrm{~nm}$; pressure at the atomizer: 1 bar; composition of gaseous bulk phase (in $\mathrm{N}_{2}$ ): $\left[\mathrm{CCl}_{4}\right]: 1.5( \pm 0.2) \times 10^{-3} \mathrm{M},\left[\mathrm{O}_{2}\right]$ : 7.5( \pm 0.4$) \times 10^{-3}$ M. ( ) : native polystyrene; $(\quad): P_{\mathrm{e}}=150 \mathrm{~W}, d: 14 \mathrm{~mm}$.

\section{Conclusions}


The up-scaling of the oxidative functionalization of particulate organic aerosols starts indeed with the generation of a sufficiently high concentration of particles. The VUV-photochemical oxidation of polystyrene films and particulate aerosols was shown to be a simple and rather efficient process that by itself could be technically developed, if other means of aerosol generation could be implemented to increase the production of particles per unit of time without addition of any kind of reagent (e.g. Rapid Expansion of Supercritical Solutions (RESS)). In the absence of corresponding investigations, the use of solutions of dissolved polymers or copolymers may offer a technical potential. Alternatively, the photochemical polymerization of liquid monomer aerosol droplets would be the method of choice for the preparation of particulate polymer aerosols, but the process is not yet technically viable.

If the advantages of the VUV-photochemical oxidation should be maintained, solvents must be found that allow the dissolution of rather high concentrations of polymer. In addition, the solvents should exhibit a relative low reactivity toward activated oxygen species, e.g. ozone. Since most organic compounds react upon excitation in the VUV-spectral domain, the product(s) of their VUV-photolysis would be used to initiate the oxidative functionalization. Tetrachloromethane $\left(\mathrm{CCl}_{4}\right)$ complies with all these conditions, its VUV-photolysis yielding $\mathrm{Cl}^{\bullet}$ that initiate the photo-oxychlorination of the organic substrate in the presence of $\mathrm{O}_{2}$.

The results of the work presented here show that the functionalization of particulate organic (polystyrene) aerosols by a combination of VUV-photolysis, photo-oxychlorination and ozonization of polystyrene is approx. 500 times more efficient than the combination of VUVphotolysis and ozonization in the absence of $\mathrm{CCl}_{4}$. However, adding photo-oxychlorination to the process of oxidative functionalization did not reduce early oxidative fragmentation of the particles.

Taking into account environmental concerns, the choice of $\mathrm{CCl}_{4}$ as a solvent and precursor of the initiated oxidation is by far not optimal. But the aim of this work was to demonstrate that the process of the oxidative functionalization of organic aerosols can be considerably enhanced by introducing an initiator into the gas phase.

\section{Experimental Section}

\section{Aerosol generation and primary functionalization}

Materials. Polystyrene foil (thickness: $0.125 \mathrm{~mm}$, Goodfellow GmbH, Germany) and tetrachloro-methane $\left(\mathrm{CCl}_{4}\right)\left(99.9 \%\right.$, Carl Roth $\mathrm{GmbH}$, Germany) were used as purchased. $\mathrm{O}_{2} 4.5$, $\mathrm{N}_{2} 5.0$ and synthetic air (Air Liquide, Germany) were used as purchased. $\mathrm{H}_{2} \mathrm{O}$ was of tridistilled quality (UHQ-II).

Aerosol generation. Aerosols were produced by means of a Collison Atomizer (Topas, ATM 220 , Germany) ${ }^{28}$, the first unit of a series of reactors and analytic equipment as described in Figure 1. 
Solutions of 0.1 to $20 \mathrm{~g}$ of polystyrene in $1 \mathrm{~L}$ of $\mathrm{CCl}_{4}$ were fed into the atomizer and dispersed into the bulk gas phase ( 1 bar). The submicron droplets were evaporated in mixing the aerosol containing the droplets with heated dry gas mixtures $\left(\mathrm{O}_{2} 4.5\right.$ and/or $\mathrm{N}_{2} 5.0$ or synthetic air). Aerosol concentration and particle diameter in function of the polystyrene concentration are shown in Figure 2. For all photochemical experiments, a polystyrene concentration of $8 \mathrm{~g} \mathrm{~L}^{-1}$ was chosen.

Oxidation of aerosols of polystyrene particles via a VUV-photo-oxychlorination process. The aerosol was led into an annular photochemical reactor $(250 \mathrm{~mL})$ that was equipped with a cylindrical $\mathrm{Xe}_{2}$-excimer radiation source emitting at $172( \pm 14 \mathrm{~nm})$ and positioned in the central axis of the reactor. The radiation source (custom built) consisted of two concentric Suprasil ${ }^{\circledR}$ quartz tubes (length: $25 \mathrm{~cm}$, outer diameter: $3.0 \mathrm{~cm}$ ) with an inner electrode (phase) made of an aluminum foil and cooled with distilled water. The $\mathrm{Xe}_{2}$-excimer radiation source was driven by a high voltage power supply (ENI, Model HPG-2) with electrical powers of 20 to $150 \mathrm{~W}$ at 175 $\mathrm{kHz}$. The radiant efficiency of the radiation source was approximately $8 \%$. An additional Suprasil $^{\circledR}$ tube was positioned between the outer wall of the radiation source and the aerosol, providing a gap for the outer electrode. This outer electrode was made of an extensible net of stainless steel (wire diameter: $0.1 \mathrm{~mm}$ ) and was connected to the ground. The gap between the two Suprasil ${ }^{\circledR}$ tubes was purged with $\mathrm{N}_{2}$ to avoid filter effects by $\mathrm{O}_{2}$. The reactor had an optical path of $7 \mathrm{~mm}$, measured between the outer Suprasil ${ }^{\circledR}$ tube and the outer reactor wall. The outer (grounded) electrode could be covered partially with a metallic sheet. This variation of the length of the irradiated zone allowed to control the total incident radiant power in the reactor. The maximum length of the irradiated zone was $140 \mathrm{~mm}$. The reactor temperature was not controlled but reached a stable working temperature of approx. $60^{\circ} \mathrm{C}$.

Comparative VUV-photolyses in liquid phase. Photo-oxychlorination reactions in liquid phase were performed in a Suprasil ${ }^{\circledR}$ spectroscopic cell $(1 \mathrm{~cm} \mathrm{x} 1 \mathrm{~cm} \mathrm{x} 4 \mathrm{~cm})$ filled with $\mathrm{CCl}_{4}$ Solutions of polystyrene $\left(8 \mathrm{~g} \mathrm{~L}^{-1}\right)$. A gas-tight cover with gas inlet and outlet closed the cell; inlet gas was carried through a capillary glass tube to the bottom of the cell. $\mathrm{N}_{2}$ or synthetic air, saturated with $\mathrm{CCl}_{4}$, were used to implement anaerobic or aerobic conditions during photolysis. The cell was irradiated by a $\mathrm{Xe}_{2}$-excimer lamp $\left(\mathrm{XERADEX}^{\mathrm{TM}}\right.$ pulsed tubular $\mathrm{Xe}_{2}$-radiation source, Radium, Germany, electrical power: $20 \mathrm{~W}$, radiant power: $8 \mathrm{~W}$ ) placed at a distance of $3 \mathrm{~mm}$ from the cell. After irradiation, $1 \mathrm{~mL}$ samples of the total volume were used for FTIR, GPC and GC/MS analyses, respectively.

\section{Particle analysis}

Samples for off-line analyses were prepared by filtering aerosol particles (Teflon-membrane filter, pore size: $0.2 \mu \mathrm{m}$ (Pall GmbH, Germany)). An up-stream connected denuder filled with charcoal was used to reduce ozonization of the accumulating particles during sampling time. After sampling, the filters were dried under high vacuum for $30 \mathrm{~min}$. 
Samples for off-line analyses taken from liquid phase photolyses were prepared by precipitation and filtration of the polymer with methanol. The remaining solvent was evaporated from the filtered at reduced pressure.

FTIR-Spectroscopy. The rates of hydroxylation and carbonylation of the polymer particle surfaces were monitored with a Bruker Golden Gate ${ }^{\circledR}$ Diamond ATR Unit mounted on a Bruker Equinox $^{\circledR} 55$ FTIR spectrometer (resolution: $3 \mathrm{~cm}^{-1}$, 60 scans per measurement). Dried filter cakes of the samples $(\S 2.2 .1$ and 2.2.2) were used without further purification.

In order to monitor and compare the evolution of particle functionalization, an oxidation index $I_{\mathrm{ox}(\mathrm{fg})}$ was defined by normalizing the integrated absorption band of one of the oxygen containing functional groups (e.g. carbonyl) with reference to the absorption band of carbon-carbon double bond that was relatively little and inversely affected by the oxidation process (equation (25)) ${ }^{14 \mathrm{~d} \text { - }}$ 16.

$$
I_{o x(C=O)}=\frac{\int A b s(t)_{C=O}}{\int A b s(t)_{r e f}}-\frac{\int A b s(0)_{C=O}}{\int A b s(0)_{r e f}}
$$

where $A b s(t)_{C=O}: \quad$ absorbance of $\mathrm{C}=\mathrm{O}\left(1615-1840 \mathrm{~cm}^{-1}\right)$ at reaction time $t$ $A b s(t)_{\text {ref }}: \quad$ absorbance of reference peaks $\left(1471-1522 \mathrm{~cm}^{-1}\right)$ at reaction time $t$ $A b s(0)_{C=O}: \quad$ absorbance of $\mathrm{C}=\mathrm{O}\left(1615-1840 \mathrm{~cm}^{-1}\right)$ for unmodified polystyrene $\operatorname{Abs}(0)_{\text {ref }}$ : absorbance of reference peaks $\left(1471-1522 \mathrm{~cm}^{-1}\right)$ for unmodified polystyrene.

UV/Vis-spectrophotometry was carried out on a HP Spectrophotometer, 8452 DAD using appropriate spectroscopic cells (optical path: $1 \mathrm{~cm}$ ) or film holders.

Particle concentrations and size distributions were monitored in-line with a Scanning Particle Mobility Sizer (SMPS) consisting of a Differential Mobility Analyzer (DMA, TSI Inc., USA, Model 3071), operated at $0.3 \mathrm{~L} \mathrm{~min}^{-1}$ aerosol flow and 3.0 $\mathrm{L} \mathrm{min}^{-1}$ sheath air, and a Condensation Particle Counter (CPC, TSI Inc., USA, Model 3022).

Gel permeation chromatography (GPC). Solutions prepared from solid samples with the eluent were analyzed without prior treatment using a HP1100 Series with DAD (200-360 nm)

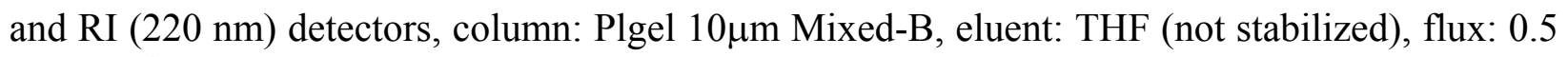
$\mathrm{mL} \min ^{-1}$, temperature: $30^{\circ} \mathrm{C}$.

Gas chromatography/mass spectrometry combination (GC/MS). Liquid samples were prepared after previous polymer precipitation with methanol and filtration, to avoid inclusions in the GC-system, and analyzed using a HP5890 with MS detector HP5973, column: HP5 MS 5\% phenyl methyl siloxane, $30 \mathrm{~m} / 250 \mu \mathrm{m}$, He, temperature: $50-250^{\circ} \mathrm{C}$, temperature gradient: $10^{\circ} \mathrm{C}$ $\min ^{-1}$, Injection temperature: $\left.270^{\circ} \mathrm{C}\right)$

X-Ray photoelectron spectroscopy (XPS). Dried filter cakes of the samples were used without further purification for XPS-analyses using an EA 125 Energy Analyser (OMICRON Electronics, Germany). 


\section{Acknowledgements}

The authors acknowledge financial support by the Deutsche Forschungsgemeinschaft (DFG) and the Landesstiftung Baden-Württemberg. XPS-analyses were made by the Institut für Physikalische Chemie, Universität Karlsruhe.

\section{References}

1. Kawaguchi, H. Prog. Polym. Sci. 2000, 25, 1171.

2. Horn, D.; Rieger, J. Angew. Chem. Int. Ed. 2001, 40, 4330.

3. (a) Pichot, C. Curr. Opinion Coll. \& Interf. Sci. 2004, 9, 213. (b) Pichot, C. Polym. Adv. Technol. 2008, 6, 427.

4. Fu, J.; Fiegel, J.; Hanes, J. Macromol. 2004, 37, 7174.

5. e.g. (a) Kim, J.-Y.; Wainaina, J.; Kim, J.-H.; Shim, J.-K. J. Nanosci. Nanotechnol. 2007, 11, 4000. (b) Dey, T. J. Nanosci. Nanotechnol. 2006, 6, 2479.

6. Saliterman, S. Fundamentals of BioMEMS and Medical Microdevices, SPIE Press, Bellingham WA, USA, 2006.

7. Willner, I.; Willner, B. Pure Appl. Chem. 2002, 74, 1773.

8. Karlsruher Symposium zum Jahr der Technik, Process Technology beyond Unit Operations, Universität Karlsruhe, Germany, 2004.

9. Salas Vicente, J. Ph.D. Thesis, Universidad Politécnica de Valencia, Valencia, Spain, 2006 (Experimental work: Lehrstuhl für Umweltmesstechnik, Universität Karlsruhe).

10. Froeschke, S.; Weber, A. P.; Kasper, G.; Salas Vicente, J.; López Gejo, J.; Bossmann, S. H.; Braun, A. M. In Handling of highly dispersed powders, Müller, E.; Oestreich, C. Eds.; Shaker, Aachen, Germany, 2004, pp 201-208.

11. Salas Vicente, J.; López Gejo, J.; Rothenbacher, S.; Sarojiniamma, S.; Gogritchiani, E.; Miranda, M. A.; Wörner, M.; Oliveros, E.; Kasper, G.; Braun, A. M. In Basics and applications of photopolymerization reactions, Fouassier, J.P.; Allonas, X. Eds.; Research Signpost, Trivandrum, India, 2010.

12. Salas Vicente, J.; López Gejo, J.; Rothenbacher, S.; Sarojiniamma, S.; Gogritchiani, E.; Kasper, G.; Braun, A. M. Photochem.Photobiol.Sci. 2009, $\underline{8}, 944$.

13. e.g. Türk, M.; Hils, P.; Helfgen, B.; Schaber, K.; Martin, H.-J.; Wahl, M. A. J. Supercrit. Fluids 2002, 22, 75.

14. (a) Pearson, R.; Langer, G. Nature 1960, 187, 235. (b) Partch, R.; Matijevi,; Hodgson, A. W.; Aiken, B. E. J. Polymer Sci., Polmer Chem. Ed. 1983, 21, 961. (c) Esen, C.; Schweiger, G. J. Colloid Interf. Sci. 1996, 179, 276. (d) López Gejo, J. Ph.D. Thesis, Universität Karlsruhe, Karlsruhe, Germany 2005.

15. López Gejo, J.; Glieman, H.; Schimmel, T.; Braun, A. M. Photochem. Photobiol. 2005, 81, 777. 
16. López Gejo, J.; Manoj, N. P.; Sumalekshmy, S.; Glieman, H.; Schimmel, T.; Wörner, M.; Braun, A. M. Photochem. Photbiol. Sci. 2006, 5, 948.

17. Ivanov, V. V.; Popov, N. A.; Proshina, O. V.; Rakhimova, T. V.; Rulev, G. B.; Saenko, V. B. Tech. Phys. Lett. 2001, 27,29.

18. Foote, C. S.; Valentine, J. S.; Greenberg, A. Active Oxygen in Chemistry; Springer, New York, 1995.

19. Wrobel, R.; Sander, W.; Kraka, E.; Cremer, D. J. Phys. Chem. A 1999, 103, 3693.

20. Gonzalez, M. C.; Oliveros, E.; Wörner, M.; Braun, A. M. J. Photochem. Photobiol. C 2004, $5,225$.

21. Quici, N.; Litter, M. I.; Braun, A. M.; Oliveros, E. J. Photochem. Photobiol. A: Chem. 2008, 197, 306.

22. (a) Braun, A. M.; Maurette, M.-T.; Oliveros, E. Technologie photochimique; Presses Polytechniques Romandes, Lausanne, Switzerland, 1986. (b) Braun, A. M.; Maurette, M.-T.; Oliveros, E. Photochemical Technology, Ollis, D. F.; Serpone, N. Transl.; Wiley, Chichester, 1991.

23. Gonzalez, M. C.; Carrillo Le Roux, G.; Rosso, J. A.; Braun, A.M. Chemosphere 2007, 69, 1238.

24. Hanf, A.; Läuter, A.; Volpp, H. R. Chem. Phys. Letters 2003, 368, 445.

25. (a) Scofield, J. H. J. Elec.Spectr. Rel. Phenom. 1976, 8, 129. (b) Wagner, C. D.; Davis, L. E.; Zeller, M. V.; Taylor, J. A.; Raymond, R. H.; Gale, L.H. Surf. Interf. Anal. 1981, 3, 211.

26. Rontu Carlon, N.; Papanastasiou, D. K.; Fleming, E. L.; Jackman, C. H.; Newman, P. A.; Burkholder, J.B. Atmos. Chem. Phys. Discuss. 2010, 10, 11047.

27. Watanabe, K.; Inn, E. C. Y.; Zelikoff, M. J. Chem. Phys. 1953, 21, 1026.

28. May, K. R. J. Aerosol Sci. 1973, 4, 235. 